\title{
Amelanotic malignant melanoma: a case study demonstrating pitfall of frequently missed opportunity for early diagnosis
}

\author{
Nursel Dilek ${ }^{1 *}$, Aziz Ramazan Dilek ${ }^{2}$, Yunus Saral ${ }^{1}$ and Ibrahim Sehitoglu ${ }^{3}$ \\ *Correspondence: nur.dilek@hotmail.com

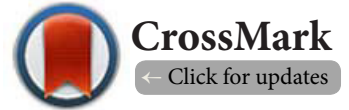 \\ 'Dermatology Department of Recep Tayyip Erdogan University, Medical Faculty Hospital, Rize, Turkey. \\ ${ }^{2}$ Microbiology Department of Recep Tayyip Erdogan University, Medical Faculty Hospital, Rize, Turkey. \\ ${ }^{3}$ Pathology Department of Recep Tayyip Erdogan University, Medical Faculty Hospital, Rize, Turkey.
}

\begin{abstract}
Malignant melanoma is the most common primary malignant tumor of the foot. Amelanotic/hypomelanotic melanoma is characterized by either little or no pigmentation and account for $2-8 \%$ of all primary melanomas. Amelanotic/hypomelanotic can often be misdiagnosed and this leads to delaying the diagnosis until advanced ulcerations depths resulted in metastases. In this report, we highlight a case of primary amelanotic melanoma of the foot treated by digital amputation.
\end{abstract}

Keywords: Amelanotic, melanoma, tumor, skin lesion

\section{Introduction}

Malignant melanoma is the most common primary malignant tumor of the foot and occurs in three different forms: superficial spreading, nodular, and acral lentiginous [1]. Amelanotic/ hypomelanotic melanoma is a non-pigmented or only slightly pigmented type of cutaneous melanoma. These cutaneous lesions are characterized by either little or no pigmentation and are defined as hypomelanotic or amelanotic, and account for $2-8 \%$ of all primary melanomas [2,3]. Amelanotic melanoma may present as a frequently eroded exophytic nodule simulating a pyogentic granuloma or haemangioma, or it can mimic a skin-colored dermal plaque, leading to delayed diagnosis until advanced depth of ulcerations results in metastases [4,5]. Here, we highlight a case of primary amelanotic melanolama of the foot treated by digital amputation.

\section{Case report}

A 57-year-old female presented with an 11-month-old painful ulcer of the 5 th toe of the right foot (Figure 1). Topical and systemic antibiotic was prescribed but the patient's complaints were undiminished. Examination revealed a painful ulcerated swollen toe. Wound culture samples were taken from the patient. In subsequent wound culture Klebsiella oxytoca was isolated, but a regimen of Ceftriaxone in accordance with antibiotic susceptibility results only improved the patient's pain symptoms but failed to resolve the ulceration. Enlarged inguinal lymph nodes were detected in a systemic examination of the patient and so an incisional biopsy sample was taken from the patient. The pathology showed an amelanotic melanoma and subsequently the patient was referred to plastic surgery (Figure 2). The patient's toe was amputated and right inguinal lymph node dissection was performed (Figure 3). Lymph nodes metastases were detected in microscopic examination (Stage III). Whole-body [18F] fluorodeoxyglucose-positron emission tomography (FDG-PET) scans were performed but pathological accumulation of FDG was not observed. Subsequently, a total dose of $50 \mathrm{~Gy}$ in 20 fractions 3D conformal radiotherapy was performed. Eventually, interferon-alfa2b was added for adjuvant therapy. After treatment, the patient was in complete clinical and radiological remission and there was no evidence of recurrence in follow-up visits for 12 months.

\section{Discussion}

Amelanotic malignant melanoma tends to occur in sun-exposed skin of elderly individuals [4]. Amelanotic melanomas comprise only $2 \%$ of melanomas and clinical features of amelanotic melanoma mimic a variety of benign and malignant skin conditions and therefore are commonly mis-diagnosed $[2,6]$. Amelanotic melanoma not only presents to dermatologists, but to other medical practitioners and represents an important diagnostic pitfall for clinicians as early diagnosis is vital $[3,6]$. Amelanotic melanoma is most commonly subungual, localized and appearing like an exophytic papular or plaque-like reddish lesion and is often ulcerated $[6,7]$. Despite the lack of pigmentation of these lesions special stains, such as the FontanaMasson stain and immunohistochemistry such as Melan-A will confirm the melanocytic nature of the lesion $[7,8]$. Common clinical misdiagnoses of amelanotic melanoma were naevus, basal cell carcinoma, seborrhoeic keratosis, verruca vulgaris, dermatitis, actinic keratosis, Bowen's disease, keratoacanthoma, dermatofibroma and pyogenic granuloma [4]. A new or changing skin lesion is the most common warning sign for melanoma 


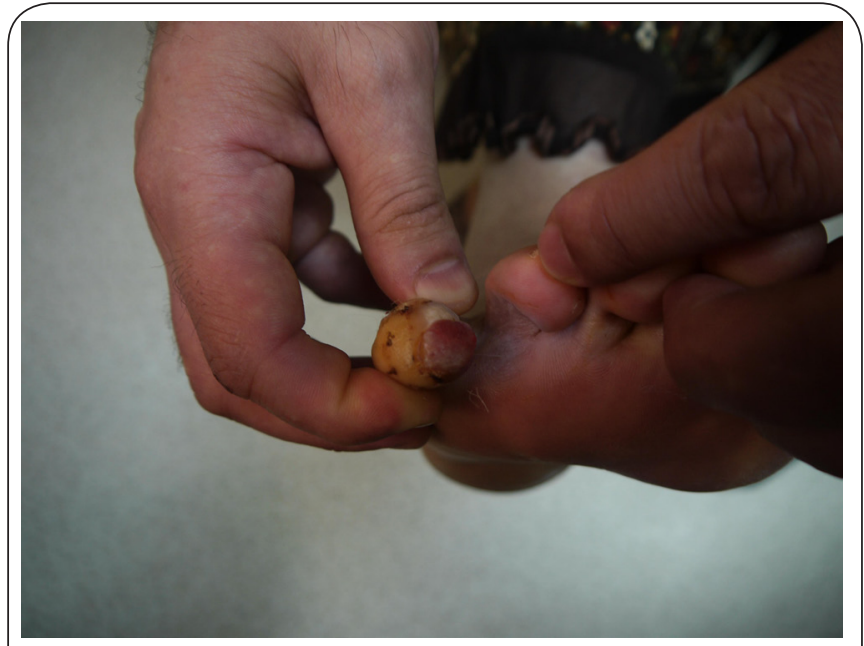

Figure 1. Ulcer of the $5^{\text {th }}$ toe of the right foot.

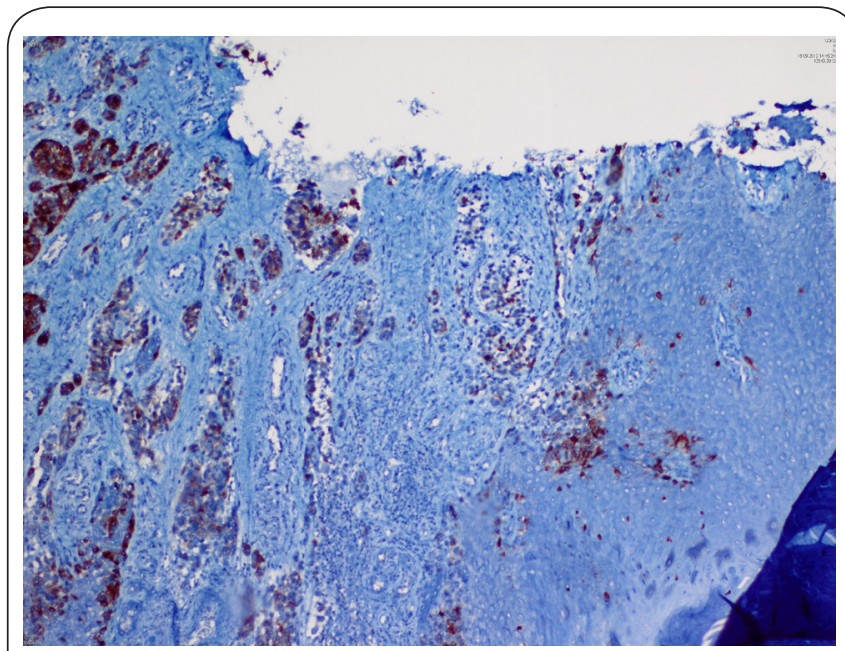

Figure 2. HMB45x100.

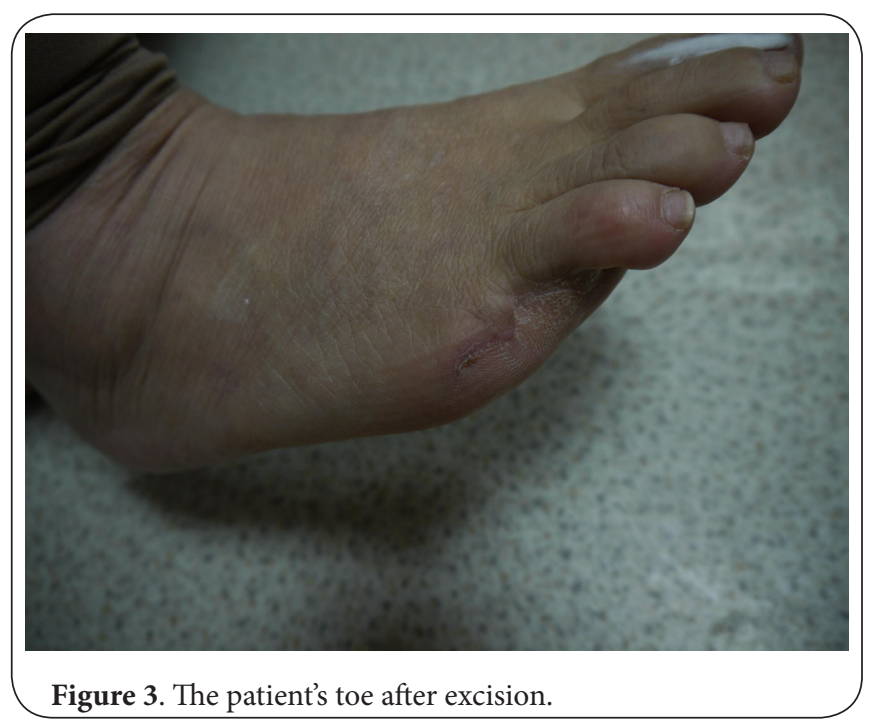

but amelanotic lesions may not be as easily recognized as malignant melanoma [9]. In approximately $50 \%$ of cases the clinical differential diagnosis ranges from inflammatory to benign neoplastic entities as in our patient who was followed for a long time (8 months) as a pyogenic granuloma in different centers [3]. In summary, though amelanotic melanoma of the foot is a rare clinicopathological entity, we recommend nonhealing foot ulcers should engender a suspicion of malignancy and demand early biopsy. This case report emphasizes the importance of early diagnosis of amelanotic melanoma for medical practitioners.

\section{Competing interests}

The authors declare that they have no competing interests.

\section{Authors' contributions}

\begin{tabular}{|l|c|c|c|c|}
\hline Authors' contributions & ND & ARD & YS & IS \\
\hline Research concept and design & $\checkmark$ & $\checkmark$ & -- & -- \\
\hline Collection and/or assembly of data & -- & -- & -- & $\checkmark$ \\
\hline Data analysis and interpretation & -- & -- & $\checkmark$ & -- \\
\hline Writing the article & $\checkmark$ & -- & -- & -- \\
\hline Critical revision of the article & -- & -- & -- & -- \\
\hline Final approval of article & $\checkmark$ & -- & -- & -- \\
\hline Statistical analysis & -- & -- & -- & -- \\
\hline
\end{tabular}

\section{Acknowledgement}

We acknowledge the patient who provided consent to have her case reported.

\section{Publication history}

Editors: Marna Elise Ericson, University of Minnesota, USA. Received: 13-Jan-2014 Revised: 20-Jan-2014 Re-Revised: 05-Feb-2014 Accepted: 10-Feb-2014 Published: 15-Feb-2014

\section{References}

1. Bristow IR and Bowling J. Dermoscopy as a technique for the early identification of foot melanoma. J Foot Ankle Res. 2009; 2:14. | Article | PubMed Abstract | PubMed Full Text

2. Zalaudek I, Argenziano G, Kerl H, Soyer HP and Hofmann-Wellenhof R. Amelanotic/Hypomelanotic melanoma--is dermatoscopy useful for diagnosis? J Dtsch Dermatol Ges. 2003; 1:369-73. | Article | PubMed

3. Jaimes N, Braun RP, Thomas L and Marghoob AA. Clinical and dermoscopic characteristics of amelanotic melanomas that are not of the nodular subtype. J Eur Acad Dermatol Venereol. 2012; 26:591-6. | Article I PubMed

4. Pizzichetta MA, Talamini R, Stanganelli I, Puddu P, Bono R, Argenziano G, Veronesi A, Trevisan G, Rabinovitz H and Soyer HP. Amelanotic/ hypomelanotic melanoma: clinical and dermoscopic features. $\mathrm{Br} J$ Dermatol. 2004; 150:1117-24. | Article | PubMed

5. Maier T, Sattler EC, Braun-Falco M, Korting HC, Ruzicka T and Berking C. Reflectance confocal microscopy in the diagnosis of partially and completely amelanotic melanoma: report on seven cases. J Eur Acad Dermatol Venereol. 2013; 27:e42-52. I Article I PubMed

6. Oburu E and Gregori A. Relearning the lesson -- amelanotic malignant melanoma: a case report. J Med Case Rep. 2008; 2:31. | Article | PubMed Abstract | PubMed Full Text

7. Rongioletti $F$ and Smoller BR. Unusual histological variants of cutaneous malignant melanoma with some clinical and possible prognostic 
Dilek et al. Dermatology Aspects 2014,

correlations. J Cutan Pathol. 2005; 32:589-603. | Article | PubMed

8. Oiso N, Yoshida M, Kawara S and Kawada A. Amelanotic vulvar melanoma with intratumor histological heterogeneity. J Dermatol. 2010; 37:537-41. | Article | PubMed

9. McClain SE, Mayo KB, Shada AL, Smolkin ME, Patterson JW and Slingluff $\mathrm{CL}$, Jr. Amelanotic melanomas presenting as red skin lesions: a diagnostic challenge with potentially lethal consequences. Int J Dermatol. 2012; 51:420-6. | Article | PubMed

\section{Citation:}

Dilek N, Dilek AR, Saral Y and Sehitoglu I. Amelanotic malignant melanoma: a case study demonstrating pitfall of frequently missed opportunity for early diagnosis.

Dermatol Aspects. 2014; 2:2.

http://dx.doi.org/10.7243/2053-5309-2-2 